\title{
Solar Hydrogen Production System Simulation Using PSCAD
}

\author{
Matouk M. Elamari \\ Electronic department Engineering Academy Tajoura Libya
}

DOI: https://doi.org/10.21467/proceedings.4.45

* Corresponding author email: matoukelamari@yahoo.com

\begin{abstract}
Hydrogen is a potential future energy storage medium to supplement a variety of renewable energy sources. It can be regarded as an environmentally-friendly fuel, especially when it is extracted from water using electricity obtained from solar panels or wind turbines. One of the challenges in producing hydrogen by using solar energy is to reduce the overall costs. It is therefore important that the system operates at maximum power. In this paper a PSCAD computer simulation based on a water-splitting, hydrogen-production system is presented. The hydrogen production system was powered by a photovoltaic (PV) array using a proton exchange membrane (PEM) electrolyser. Optimal matching between the PV system and the electrolyser is essential to maximise the transfer of electrical energy and the rate of hydrogen production. A DC/DC buck converter is used for power matching by shifting the PEM electrolyser I$\mathrm{V}$ curve as closely as possible toward the maximum power the PV can deliver. The simulation shows that the hydrogen production of the PV-electrolyser system can be optimised by adjusting the converter duty cycle generated by PWM circuit.
\end{abstract}

Keywords - Renewable - photovoltaic- solar hydrogen- PEM electrolyser.

\section{Introduction}

In recent years, the central aim of world energy policy has been to develop renewable energy sources and share the energy they produce to reduce dependence on fossil fuels and to reduce the harmful emissions that result when they are burned. To fully take advantage of the environmental benefits of hydrogen, it must be produced from a renewable feedstock (renewable energy), but most of the hydrogen that is currently produced is derived from natural gas, which is a non-renewable fossil fuel.

Hydrogen produced from renewable energy sources offers the promise of a clean, sustainable energy carrier that can be produced from domestic energy resources around the globe. One method of hydrogen production using a renewable energy source is the electrolysis of water using renewable electricity, i.e., electricity generated from photovoltaic cells, wind turbines, hydroelectric turbines, or generators fuelled by biomass.

(C) 2018 Copyright held by the author(s). Published by AIJR Publisher in Proceedings of First Conference for Engineering

Sciences and Technology (CEST-2018), September 25-27, 2018, vol. 2 .
This is an open access article under Creative Commons Attribution-NonCommercial 4.0 International (CC BY-NC 4.0)

AiR license, which permits any non-commercial use, distribution, adaptation, and reproduction in any medium, as long as the original work is properly cited. ISBN: 978-81-936820-6-7 
Solar Hydrogen Production System Simulation Using PSCAD

Several potential applications for electrolysis use solar- and wind-produced electricity. Solar PV cells and wind turbines convert solar energy and wind power, respectively, into electricity that can be used to produce hydrogen from water by electrolysis. Electrolysis using solar energy is a very attractive process to produce hydrogen. The exploitation of this important potential comes through the conversion of the solar energy to an energy vector that is versatile, storable, transportable and ecologically acceptable. Today, hydrogen seems to be the best candidate

\section{Components of the solar hydrogen production system}

Hydrogen production through water electrolysis using solar photovoltaic cells to provide the required electricity is highly feasible. Both water and solar energy are available in huge amounts, and hydrogen provides an ideal means for storing and transporting electricity from solar energy. The PV uses light to generate DC electrical energy. The PV cell consists of one or two layers of a semi-conducting material ( $\mathrm{p}$-n junctions), usually silicon. When light shines on the cell, an electric field is created across the layers, which causes electricity to flow. The greater the intensity of the light, the greater the more power the PV cell delivers. The electric current produced by the PV cell is passed through water in an electrolyser, and the water molecules separate into hydrogen and oxygen. The most common electrolyser uses a proton exchange membrane (PEM) as a catalyst in the electrolysis process. In comparison to electrolysers that use a liquid electrolyte that must be replenished frequently, the PEM electrolyser has the advantages of producing very pure hydrogen, and requiring much less maintenance. In addition, it has easily scalable cells, and it can operate at much higher current densities than other types of electrolysers (1-2 A/ cm2), with conversion efficiencies ranging from $50-90 \%$. As mentioned earlier, electrolysers are thought to be a potentially cost-effective way of producing hydrogen locally. Electrolysers are compact and can realistically be located at existing fuelling places. Also, they offer a way to produce hydrogen with electrical power generated from renewable sources. Currently, renewable sources, such as solar, wind, and hydropower, produce only electricity, but the electricity they generate can also be used to produce hydrogen fuel through the use of electrolysers.

Figure 1 shows a PV hydrogen production system, which usually consists of the following main components: a PV array to supply the DC power to the system and PEM electrolyser; and DC-DC converter that consists of a control unit for power matching between the PV material and the PEM electrolyser and for providing the delivery of maximum power by PV material to maximize the hydrogen production rate.

Studies have been conducted on connecting solar PVs directly to an electrolyser (shown by the dotted path), thereby avoiding the need for a DC-DC converter. However, in this case, PV modules are not optimized to supply the most power the PV modules can deliver.

ISBN: 978-81-936820-6-7 


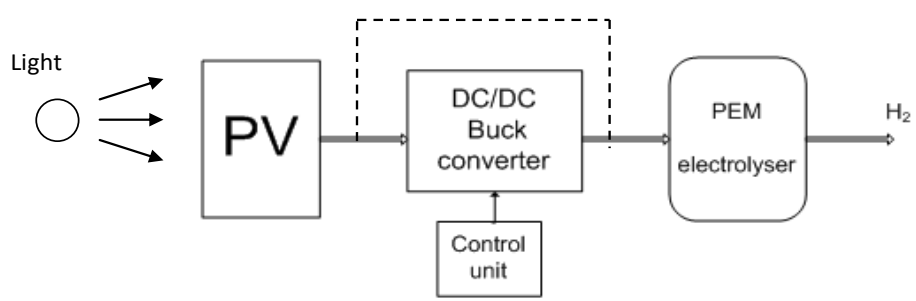

Figure 1: Block diagram of a $P V$ hydrogen production system

One of the challenges in producing hydrogen by using solar energy (PV-Hydrogen system) is to reduce the cost. Therefore, it is important that the system operate at maximum power. This operation is usually achieved by matching the power generated by the PV cell with the power required to produce hydrogen.

\section{PSCAD simulation}

This part describes the use of PSCAD/EMTDC software to simulate the performance of a solar PV-PEM hydrogen production system.

System components:

Only the essential solar hydrogen production system components are included in this simulation programme. These components are the photovoltaic module, the DC-DC buck converter and the proton exchange membrane electrolyser.

The input data to the simulation programme are the solar irradiance hits the photovoltaic module, and the ambient temperature. The output results of the simulation are:

- Characteristics of the photovoltaic current, voltage, and power at standard test conditions $\left(1000 \mathrm{~W} / \mathrm{m}^{2}\right.$ and $\left.25^{\circ} \mathrm{C}\right)$.

- Current and voltage readings at the input and output of the DC-DC buck converter

- Characteristics of the electrolyser's current and voltage

- Characteristics matching of the photovoltaic source and the electrolyser

- The operating current of the system

- Hydrogen production rate

\section{$4 \quad$ PV Model}

The PV solar cell was modelled in PSCAD/EMTDC, as shown in Figure 2 There are two inputs and two outputs in this block. The inputs are terminal voltage and irradiance. The

Proceedings of First Conference for Engineering Sciences and Technology (CEST-2018), vol. 2 